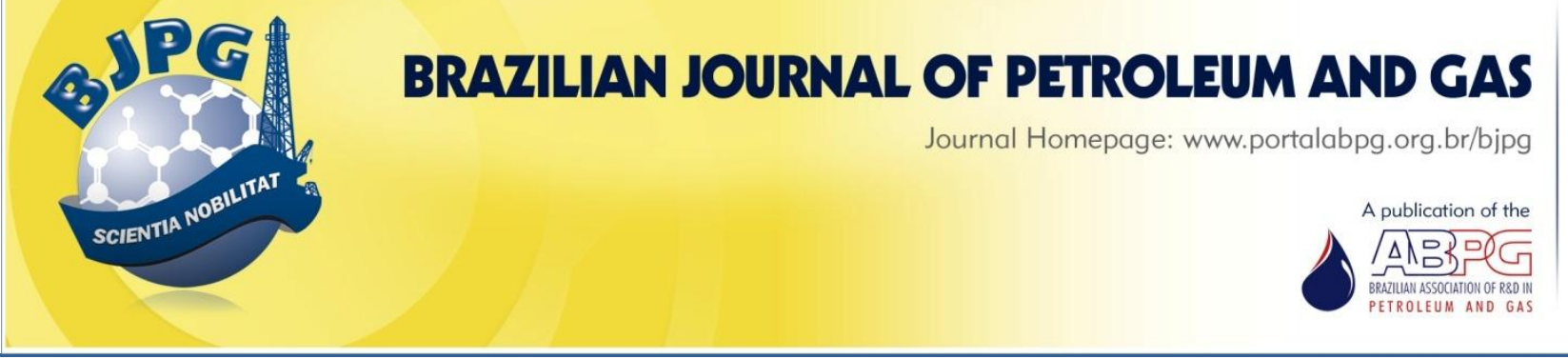

\title{
ANALYSIS OF THE THERMAL EFFICIENCY FOR A STEAM INJECTION PROCESS APPLIED TO A THIN HEAVY OIL RESERVOIR FROM THE NORTHEAST OF BRAZIL
}

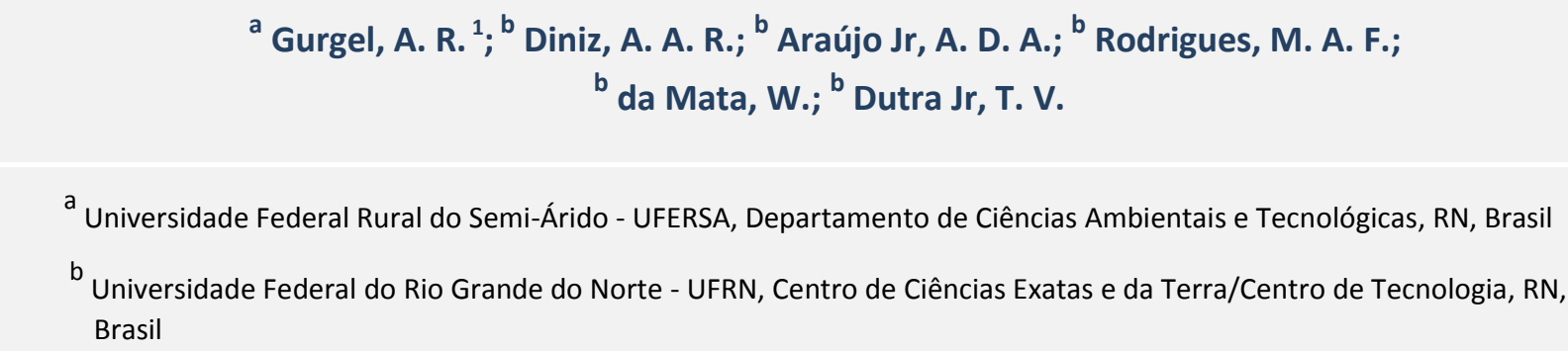

\section{ABSTRACT}

The use of steam injection in the recovery of heavy oils leads to improved results. During the process, only a fraction of the injected heat will warm up the porous media effectively due to heat losses within the injection lines and to formations adjacent to the productive zone. One way of measuring the amount of heat present in the porous media is through thermal efficiency. Therefore, this research proposes a more accurate way of investigating the amount of heat provided and actually used within the reservoir rock. To perform this study, a semi synthetic numerical model was developed, in a system with a Cartesian grid. It used a high viscosity oil, similar to those found in the Northeast region of Brazil, specifically in the Potiguar Basin, produced through an inverted quarter five spot. By varying the operational parameters (steam injection and steam quality), one observed the behavior of thermal efficiency curves, through a period of 15 years, for an oil net pay of $10 \mathrm{~m}$. The study concluded that high steam qualities and steam injection rates were associated to the lowering of the fraction of the remaining heat at the end of the project. Also, increased values of steam injection rates resulted in higher thermal efficiencies, before the steam breakthrough.

\section{KEYWORDS}

heavy oil; numerical simulation; reservoir; steam injection; thermal efficiency

\footnotetext{
${ }^{1}$ To whom all correspondence should be addressed. Address: Universidade Federal Rural do Semi-Árido - UFERSA, Departamento de Ciências Ambientais e Tecnológicas - DCAT Av. Francisco Mota, 572, Bairro Costa e Silva, Mossoró/RN/Brasil | CEP: 59.078-970 Phone: +55 84 99633-9919 |e-mail: robsongurgeleq@yahoo.com.br doi:10.5419/bjpg2015-0013
} 


\section{INTRODUCTION}

One way of studying the technical viability of exploring heavy oils is through numerical simulation, which can be applied to support the development of new field projects, besides making possible to control those already being exploited (Satik et al., 2004). Its use includes the evaluation and planning of multiple operation strategies, and, when used properly, it can be one of the most sophisticated and detailed existing tools for following and predicting oil and gas recoveries. Coats et al. (1974) reported that, when evaluating input data reliability, complexity and level of sophistication have to be consistent with the objectives of the project.

Heavy oil recovery relates to the application of processes known as enhanced oil recovery methods. Among those methods, the thermal ones stand out. According to Green \& Willhite (1998) and Barillas et al. (2008), the latter methods can be subdivided in hot fluids injection (water and steam) and in-situ combustion. When the heat is introduced within the reservoir, many phenomena can happen simultaneously in that porous media, which can include: fluid's viscosity reduction, distillation of lighter components, and oil volume changes.

When an oil reservoir is heated by the injection of hot fluids, a significant amount of the injected energy is lost for those adjacent formations. The fraction of the injected heat that remains within the reservoir, to heat it, known as thermal efficiency, is independent from the thermal method used, which can be either combustion or injection of hot fluids. The thermal efficiency, before the arrival of the steam front to the producer well (breakthrough), is more dependent on the project time than on other operational conditions (Prats, 1969).

This study considered a homogenous and semisynthetic model, produced through an inverted quarter five spot, and modeled with characteristics similar to those ones found in the Northeast of Brazil, especially in the Potiguar Basin. From this base model, a design of experiments (DOE) was performed and a factorial planning with $3^{3}$ cases was defined, resulting in 27 cases (simulations). The evaluation of this system used STARS (Steam, Thermal, and Advanced Processes
Reservoir Simulator), a commercial numerical simulator, created by the CMG (Computer Modeling Group). This research aims at investigating how the thermal efficiency is influenced by steam injection rate, steam quality, operational parameters to improve the fraction of remaining heat applied to hydrocarbons within the reservoir rock.

\section{METHODOLOGY}

To create the reservoir's numerical model, the methodology was divided in two steps, as detailed below. First, the model considered the adjustment of the rock-fluid data using the numerical simulator. The second step included the implementation of the way of calculating the thermal efficiency on the commercial simulator.

\subsection{Adjustment of the rock-fluid data on the numerical simulator}

Table 1 presents the rock-fluid data used for the numerical model.

Table 1. Grid dimensions and reservoir properties.

\begin{tabular}{|c|c|}
\hline Properties & Values \\
\hline Reservoir area $\left(\mathrm{m}^{2}\right)$ & $100 \times 100$ \\
\hline Oil zone thickness, $\mathrm{h}(\mathrm{m})$ & 10 \\
\hline Reservoir depth (m) & 200 \\
\hline Number of blocks through $\mathrm{i}, \mathrm{j}, \mathrm{k}$ & $25,25,10$ \\
\hline $\begin{array}{l}\text { Average oil saturation in the pay } \\
\text { zone (\%) }\end{array}$ & 64 \\
\hline Horizontal permeability (Kh, mD) & 1000 \\
\hline Vertical permeability $(\mathrm{Kv}, \mathrm{mD})$ & $0.1 \times \mathrm{Kh}$ \\
\hline Porosity (\%) & 24 \\
\hline Initial temperature (K) & 310.93 \\
\hline $\begin{array}{l}\text { Initial pressure at the top of } \\
\text { reservoir }(\mathrm{kPa})\end{array}$ & $1,992.035$ \\
\hline Original oil in place $\left(\mathrm{m}^{3}\right)$ & $25,934.1$ \\
\hline $\begin{array}{l}\text { Effective compressibility of } \\
\text { formation, } 1 / \mathrm{kPa}\end{array}$ & $4.35 \times 10^{-4}$ \\
\hline $\begin{array}{l}\text { Injection well maximum pressure } \\
\text { constraint, } \mathrm{kPa}\end{array}$ & $7,196.14$ \\
\hline $\begin{array}{l}\text { Production well minimum pressure } \\
\text { constraint, } \mathrm{kPa}\end{array}$ & 196.45 \\
\hline
\end{tabular}




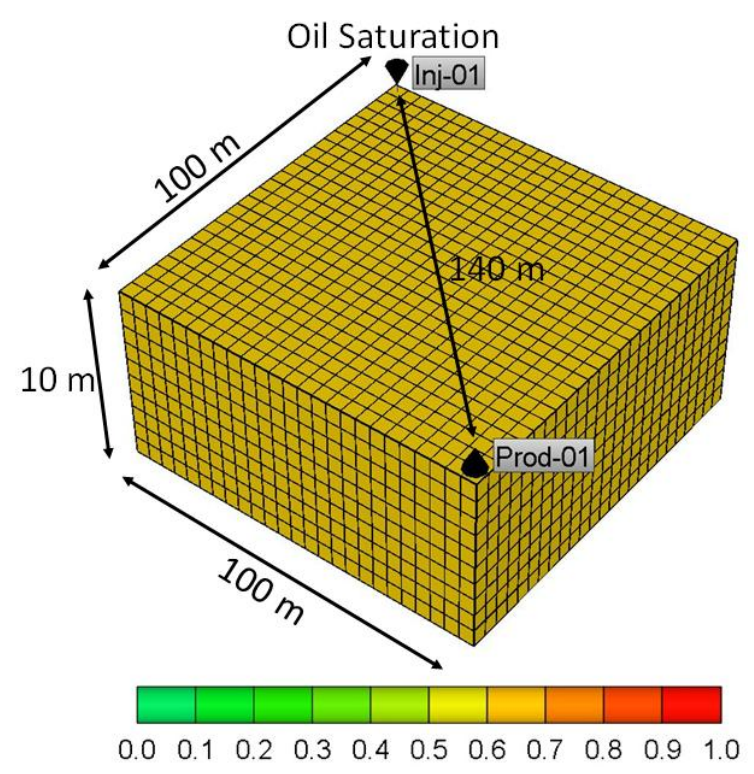

Figure 1. System's 3D model.

Figure 1 shows the physical dimensions of the numerical model created on the commercial simulator. As one can observe in Figure 1, the model represents an inverted quarter five spot configuration, with the dimensions of $100 \mathrm{~m} x$
$100 \mathrm{~m}$, oil net pay of $10 \mathrm{~m}$ (with no water zone), and a distance between the injector and producer wells of $140 \mathrm{~m}$.

The fluid (viscous heavy oil) was modeled by using the WinProp commercial simulator, by the CMG (Computer Modeling Group Ltd.), with characteristics similar to those ones found in the Potiguar Basin, an onshore field located in the Northeast of Brazil. The fluid's model took into consideration the differential liberation data, obtained from the oil sample, containing the following pieces of information: oil formation volume factor $(B o)$; solution gas/oil ratio (Rs); fluid's density $\left(\rho_{o}\right)$, and oil viscosity $\left(\mu_{\circ}\right)$. These experimental data were adjusted, according to thermodynamic functions available on the software and Peng-Robinson equations of state, to create curves close to the ones of the available data. Figure 2 presents the experimental data (red points) for $B o(a)$, Rs (b), $\rho_{o}(c)$, as a function of the pressure, and for $\mu_{o}(d)$, as a function of the temperature, and also their adjusted curves. The software performed the adjustments.
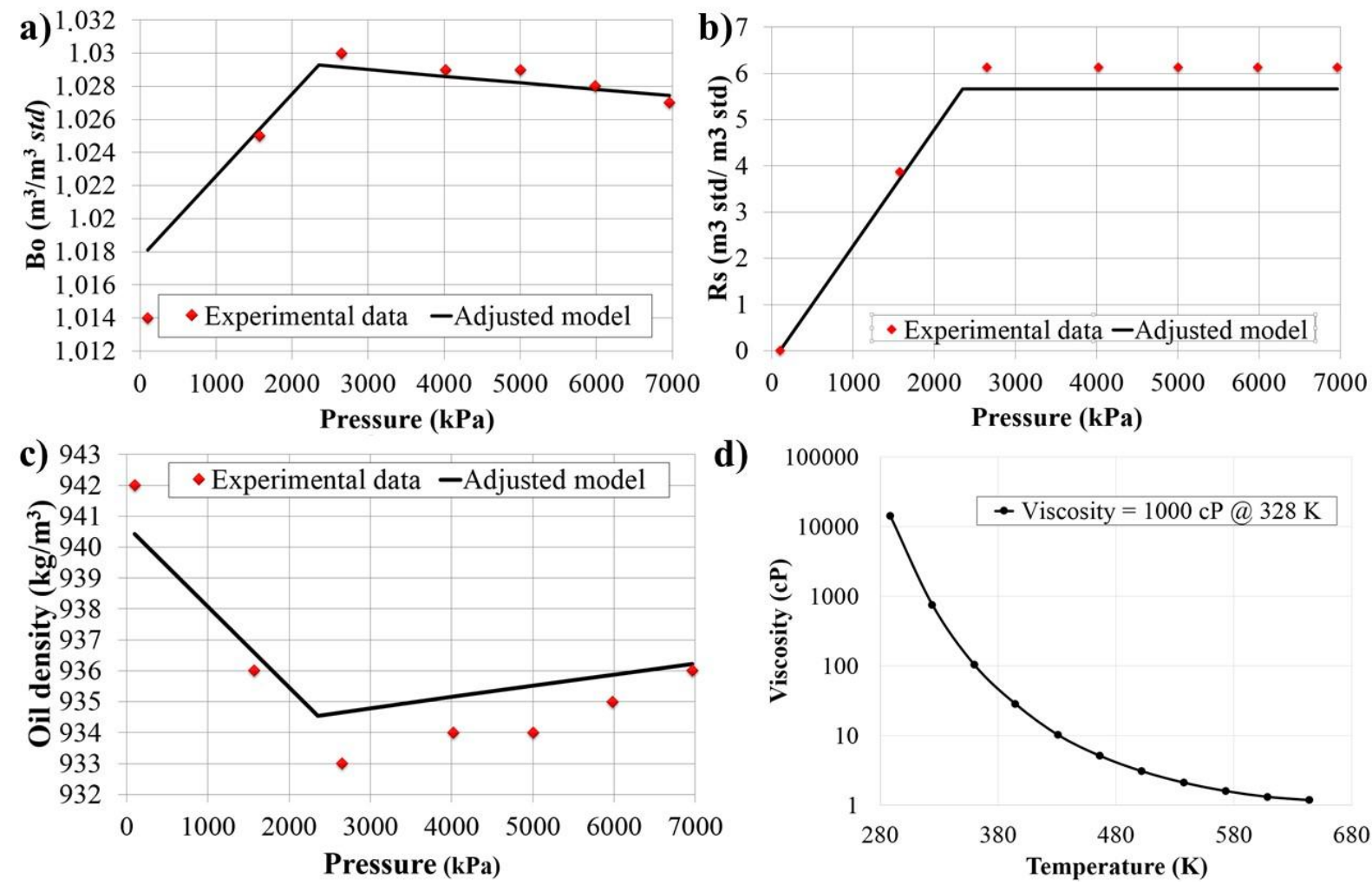

d) 100000

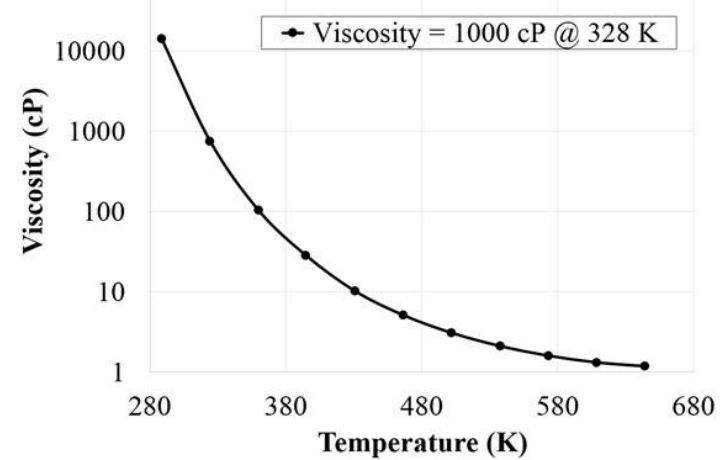

Figure 2. Comparison between experimental data and the adjustment performed by the software for the oil formation volume factor (Bo); solution gas/oil ratio (Rs); fluid's density $\left(\rho_{\mathrm{o}}\right)$, and oil viscosity $\left(\mu_{\mathrm{o}}\right)$. 
Table 2. Operational parameters of the reservoir's numerical model.

\begin{tabular}{lc}
\hline \multicolumn{1}{c}{ Operational parameter } & Value \\
\hline Steam quality $(\%)$ & 50 \\
Steam injection rate (t/day) & 25 \\
Surface liquid rate $\left(\mathrm{m}^{3}\right.$ std/day) & 100 \\
Minimum pressure for the producer well & 200.5 \\
$(\mathrm{kPa})$ & \\
Maximum injection pressure $(\mathrm{kPa})$ & 7,198 \\
Steam temperature $(\mathrm{K})$ & 561 \\
\hline
\end{tabular}

The data defined for the operational parameters are presented in Table 2.

These operational parameters were chosen based on operational criteria usually adopted by the teams that work in the studied region (Potiguar Basin).

\subsection{Implementation of thermal efficiency evaluation on the commercial simulator}

To generate thermal efficiency curves on the simulator, the thermal efficiency $(E h)$ equation had to be rewritten. Thermal efficiency can be defined as the fraction of the net injected heat that remains within the reservoir (Prats, 1969) and can be written as a function of the total net injected heat $\left(Q_{i n j}\right)$ and the heat lost to the adjacent formations $\left(Q_{l}\right)$ in the following ways:

$$
E h=1-\frac{Q_{l}}{Q_{i n j}}
$$

or

$$
E h=\frac{Q_{l i n j}-Q_{l}}{Q_{i n j}}
$$

Where, $Q_{\text {linj }}$ is the amount of the net injected heat, which is the difference between the total heat, injected by all the injector wells, reduced by the heat produced by all the production wells.

Mathematically, $Q_{\operatorname{linj}}$ can be expressed as:

$$
Q_{\text {linj }}=Q_{\text {inj }}-Q_{\text {prod }}
$$

Where, $Q_{\text {prod }}$ is the heat produced by the reservoir's producer wells.

The remaining heat within the reservoir $\left(Q_{r m}\right)$ is the difference between the total net injected heat $\left(Q_{\text {linj }}\right)$ and the heat lost to formations, from the top and base, $\left(Q_{1}\right)$. It is expressed by the Equation (4) as follows:

$$
Q_{r m}=Q_{l i n j}-Q_{l}
$$

Which can be written, in terms of the total injected and produced heats, as:

$Q_{r m}=Q_{i n j}-Q_{\text {prod }}-Q_{l}$

Thus, Equation (2) is now written as a function of $Q_{a c}, Q_{l}$, and $Q_{l i n j}$, as:

$E h=\frac{Q_{i n j}-Q_{\text {prod }}-Q_{l}}{Q_{i n j}-Q_{\text {prod }}}$

or

$E h=\frac{Q_{r m}}{Q_{l i n j}}$

Equation (7) was used in the commercial simulator to generate thermal efficiency curves as a function of the simulation time for all cases studied.

For this study, the commercial simulator and the analytic model had their operational and reservoir parameters defined according to the influence criteria imposed by the equations proposed by Marx \& Langenheim (1959), Prats (1969), Mandl \& Volek (1969), and Myhill \& Stegemeier (1978). Gomaa (1980), in his research, concluded that very thick reservoirs, with high steam injection rates and steam qualities, would improve oil recovery efficiency. Hence, steam injection rate $\left(Q_{i n j}\right)$ and steam quality $(X(\%))$ were selected to be the operational parameters evaluated in this study.

Based on the criterion of the recovery factor as a function of the injected pore volume (IPV), a study was performed to choose the three levels of the injection rate. These levels were defined as minimum (-1), intermediate (0), and maximum (+1) levels. 
Table 3. Design of experiments (DOE): full factorial planning, with $3^{3}$ cases.

\begin{tabular}{cccc}
\hline Variables & \multicolumn{3}{c}{ Levels } \\
\hline$Q_{\text {inj }}(t /$ day $)$ & 20 & 25 & 30 \\
$X(\%)$ & 25 & 50 & 75 \\
$c(\%)$ & 50 & 70 & 100 \\
\hline
\end{tabular}

Table 4. Steam injection rates for the thickness of $10 \mathrm{~m}$.

\begin{tabular}{c|c}
\hline \multirow{4}{*}{$Q_{\text {inj }}($ t/day $)$} & $h=10 m$ \\
\cline { 2 - 2 } & 15 \\
& 20 \\
& 25 \\
& 30 \\
& 35 \\
& 40 \\
& 45 \\
\hline
\end{tabular}

The IPV was defined as the quotient between the cumulative volume of the injected steam over time and the reservoir pore volume. Mathematically, it can be expressed by Equation (8):

$$
I P V=\frac{\sum \text { Winj }}{P V}
$$

Where $W_{i n j}$ is the cumulative volume of injected steam, $m^{3}$, and PV is the pore volume, $\mathrm{m}^{3}$.

Therefore, based on $R F$ and IPV, numerical simulations were performed and charts of recovery factor in function of IPV were created to make possible verifying the points where it could be obtained high $R F$ values with low IPV values. This procedure was adopted to define an adequate interval of flow rates to be used for the oil net pay of $10 \mathrm{~m}$.

The uniqueness of this study is that it evaluates the thermal efficiency as a function of time and not as a function of dimensionless time, once that the commercial simulator does not express its results in dimensionless time. Moreover, in the oil industry, it is more common to evaluate EOR projects, as a function of time, in years. Results were obtained for different values of heat injection, produced heat, and heat lost to adjacent formations. All these energies were analyzed cumulatively in time. The analyses did not use analytical models obtained from mathematical hypothesis, despite knowing that the equation for the thermal efficiency, implemented in the simulator, was based on the study of analytical models obtained from important authors.

The full factorial design defined for this research, with $3^{3}$ cases, had the parameters and factors shown in Table 3.

Table 3 lists the following input parameters: steam rate $\left(Q_{i n j}\right)$, steam quality $(X(\%))$, and well completions $(c(\%))$ for the producer and injector wells, which are expected to influence the thermal efficiency for a 15 -year project. In this case, $c$ $(\%)=100$ means that, for an oil net pay of $10 \mathrm{~m}$, both injector and producer wells are completed for the entire interval (oil zone).

\section{RESULTS AND DISCUSSIONS}

Table 4 presents the injection rates to be tested in this reservoir with $10 \mathrm{~m}$ of thickness and oil net pay. During this analysis, all the reservoir parameters (horizontal $\left(K_{h}\right)$ and vertical $(K v)$ permeabilities, porosity $(\varphi)$, fluid saturation $(S)$ ) and some operational parameters (distance between wells $(d)$, wells completion $(c(\%))$, steam quality $(X(\%))$ were kept constant. The present comparative study varied the steam injection rate $\left(Q_{i n j}\right)$ to determine the recovery factor $(R F(\%))$ and the injected pore volume (IPV). The goal was to obtain the highest oil recovery, minimizing the injected pore volume, and to choose the three levels of the steam injection rate. For these tests, the steam quality $(X(\%))$ was kept at $50 \%$, and the well completion $(c(\%))$ was set at $100 \%$.

Table 5 presents results for the oil recovery factor, as a function of time, for all the simulations performed in this reservoir, with the thickness (oil net pay) of $10 \mathrm{~m}$. From Table 5 , one can observe that the highest oil recovery factor was obtained by injecting a steam rate of $20 \mathrm{t} /$ day. However, the steam injection rate increase resulted in successive oil recovery factor decreases. This result probably is associated to the anticipation of the steam breakthrough, which happens as a result of increasing the steam injection rate, reducing the accumulation of pressure within the reservoir rock. This effect will be reviewed later in this paper. 
Table 5. Oil recovery factor (\%RF) for seven steam injections, during 15 years of simulation time, considering the reservoir thickness (oil net pay) of

\begin{tabular}{cc}
\multicolumn{2}{c}{$10 \mathrm{~m}}$. \\
\hline Rate (t/day) & \%RF \\
\hline 15 & 47.70 \\
20 & 82.91 \\
25 & 82.57 \\
30 & 81.62 \\
35 & 80.78 \\
40 & 79.99 \\
45 & 79.28 \\
\hline
\end{tabular}

To understand what happens within the reservoir rock, gas saturation maps were ser, as shown in Figure 3, considering two steam rates (20 t/day and 45 t/day), in two different project times (6 and 15 years). Those values were chosen because, according to the results presented in Table 5, they represent the highest FR $\left(Q_{i n j}=20\right.$ $t /$ day $)$ and the lowest $\left(Q_{i n j}=45 t /\right.$ day $)$ values.

Figure 3 shows that, for 6 years of production, early gas production occurred in the case where the steam injection was $45 \mathrm{t} /$ day, when compared to the one where the steam injection was $20 \mathrm{t} /$ day. On the other side, at the final project time (15 years), one could verify that, by keeping the injection rate at $20 \mathrm{t} /$ day, largest amount of swept oil took place. It shows that the effect of the oil displacement by the steam was stronger when it used lower steam rates, even when the time to recover the oil was more expressive.

A possible explanation to these phenomena can be obtained by analyzing pressure maps though the time, showed in Figure 4.

As seen in Figure 4, a higher amount of recovered oil is associated with a higher pressure level stored in the porous media, which was obtained by injecting the steam rate of $20 \mathrm{t} /$ day (a, $c$, and e). This may be associated to the delay of the steam breakthrough, which favors the accumulation of pressure (represented through the time by the average pressure ' $P$ ') and energy, in the way of steam, giving a higher swept efficiency, when compared to the case where the steam was injected with the highest rate.

An evaluation of the oil recovery factor in function of IPV (injected pore volume) is presented in Figure 5. In this figure one can observe that the first sharp change in the curves (between 1.5 and 2.5 IPVs) represents the steam volume needed to the arrival of the warm steam bank to the producer well. On the other side, the second sharp change (from 3.5 IPVs) is related to the volume of steam needed to reach the highest oil recovery factor. One can also verify that the highest oil recovery

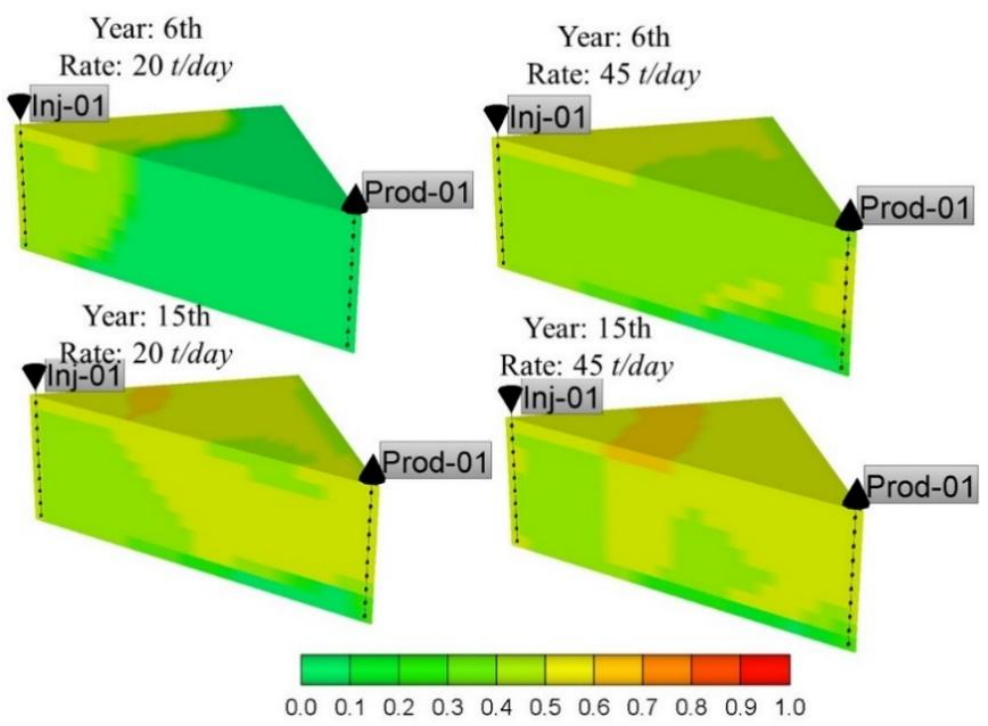

Figure 3. Gas saturation maps for two different steam rates ( $20 \mathrm{t} /$ day and $45 \mathrm{t} /$ day) in the $6^{\text {th }}$ and $15^{\text {th }}$ year (final project time), considering the oil net pay of $10 \mathrm{~m}$. 


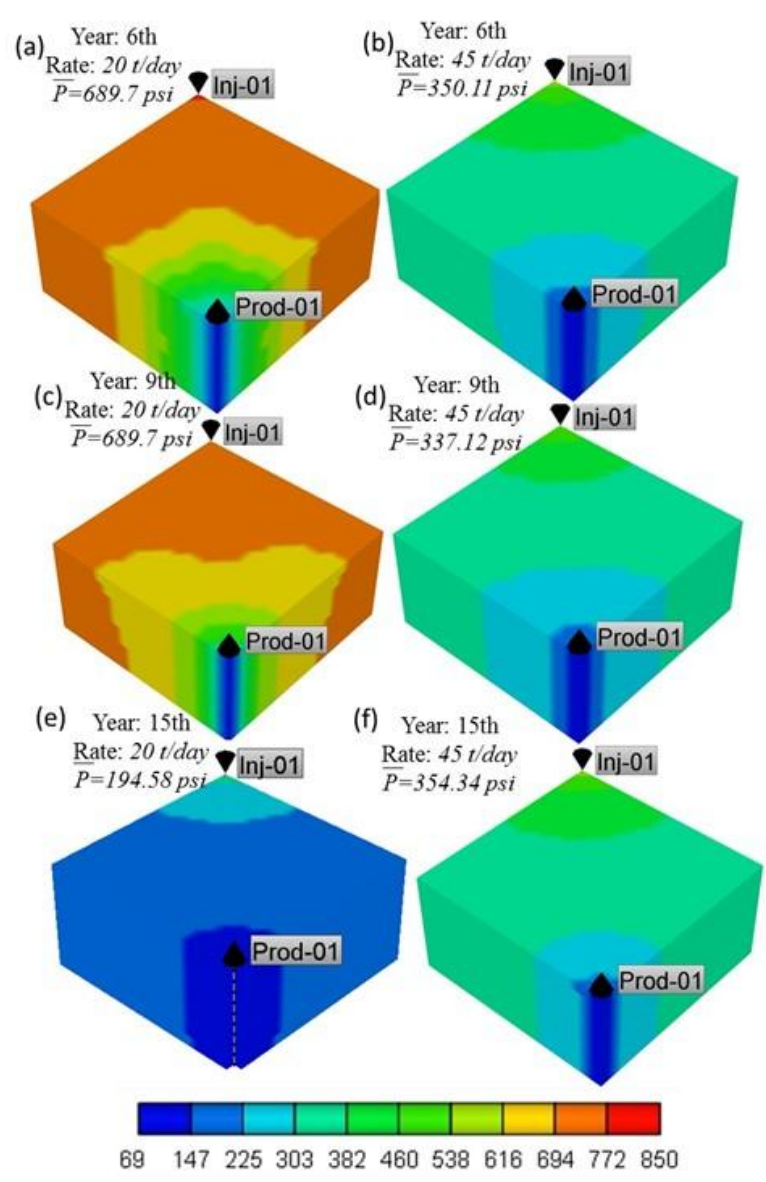

Figure 4. Pressure maps (psi) for the steam rates of $20 \mathrm{t} /$ day and $45 \mathrm{t} /$ day.

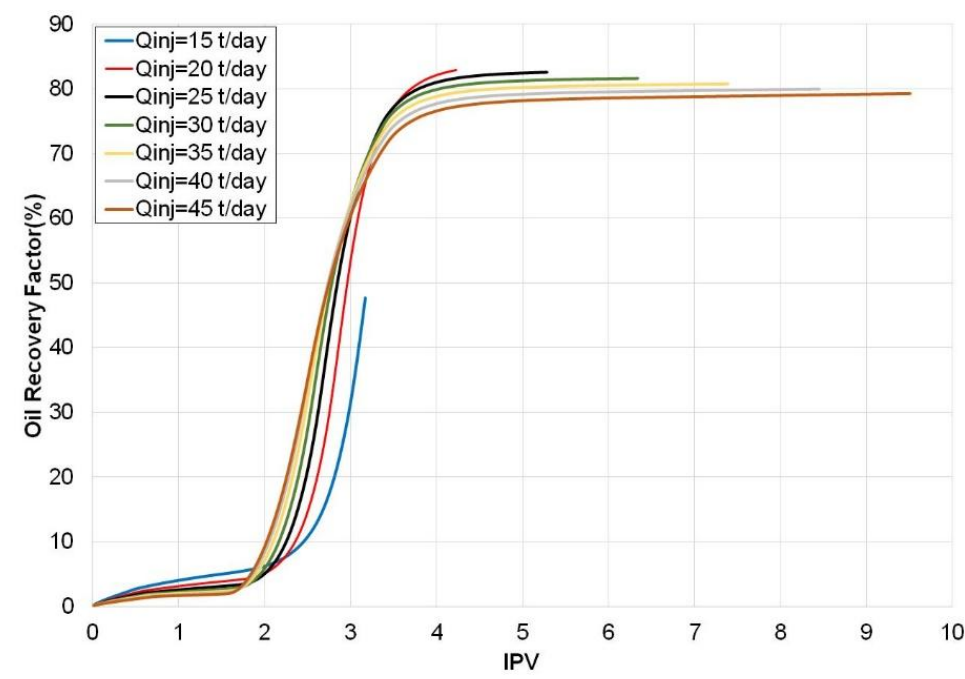

Figure 5. Curves of RF in function of IPV, for seven different steam rates, considering the oil net pay of $10 \mathrm{~m}$.

(last point reached by each RF curve) is reached for an IPV of about 4.2. Hence, injecting more than 4.2 means wasting energy because, based on Figure 5, there is no increase in oil recovery factor for higher steam injection rates. On the contrary, when the steam injection rate is increased above $20 \mathrm{t} /$ day there is a decrease in the oil recovery factor. However, to analyze the oil recovery factor and thermal efficiency, the best injection rate $(20$ $\mathrm{t} /$ day) along with two more rates ( $25 \mathrm{t} /$ day and 30 $t /$ day) were selected, presenting the $2^{\text {nd }}$ and $3^{\text {rd }}$ highest oil recovery factors. 


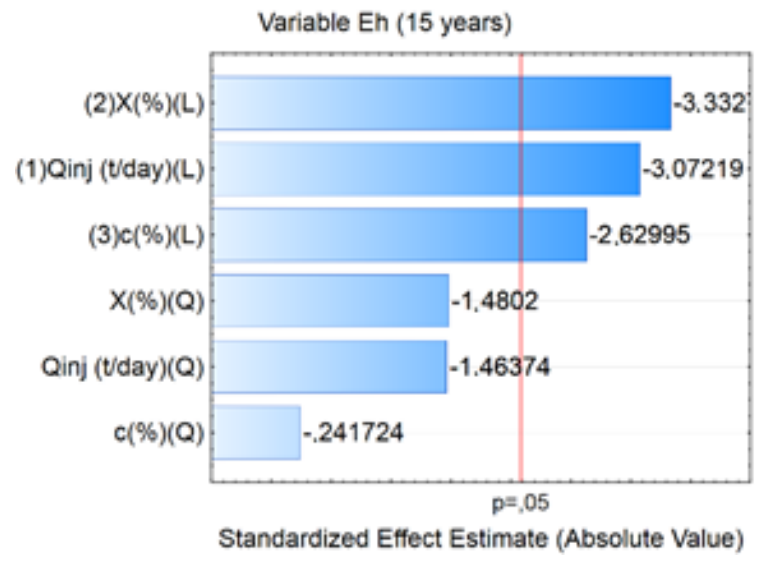

Figure 6. Pareto chart used for evaluating the thermal efficiency $(E h)$, in 15 years, considering a reservoir thickness of $10 \mathrm{~m}$ (oil net pay).

After defining the steam rates to be tested, the thermal efficiency was analyzed as a function of the following operational parameters of the numerical model: steam injection rate $\left(Q_{i n j},\right)$, steam quality $(X(\%))$, and well completion $(c(\%))$ for producer and injector wells. For this analysis, it was performed a full factorial planning, with $3^{3}$ cases, which resulted in 27 simulations, combining the parameters and levels listed in Table 3. This study was evaluated statistically by creating a Pareto chart.

From simulation results, a Pareto chart, shown in Figure 6, summarized the data of the15-year project. This analysis studied the interactions among those operational parameters, identifying the ones statistically more significant in terms of thermal efficiency at the end of the project time.

Figure 6 presents, in descending order, individual effects of the following parameters: steam quality $(X(\%))$, steam injection rate $\left(Q_{i n j}\right)$, and well completions $(c(\%))$. From the chart, one can verify that linear effects of steam quality $(X$ $(\%))$, steam injection rate $\left(Q_{i n j},\right)$, and well completions (c (\%)) influenced negatively the thermal efficiency $(E h(\%))$. In relation to the first two parameters, this answer can be associated to high heat losses on the way to the producer well, after the heat breakthrough, when the steam is injected with high rates and steam qualities. In this scenario, there is a decrease in the remaining heat, while there is an increase in the heat production after the heat breakthrough. Regarding the well completion, high values of this parameter result in decreasing the thermal efficiency. This can be due to the fact that, by having a longer interval of well completion $(c(\%)=100)$, there is a bigger area open to the heat flow in the producer well, what favors a high heat production through the well, contributing to the reduction of the thermal efficiency.

From Figure 7, one can observe that, by keeping the well completion in $c(\%)=100$ and the steam quality in $X(\%)=50$, there is a continuous decrease in the fraction of the remaining heat over the time. Besides that, higher values of steam injection rate resulted in a higher thermal efficiency, before the

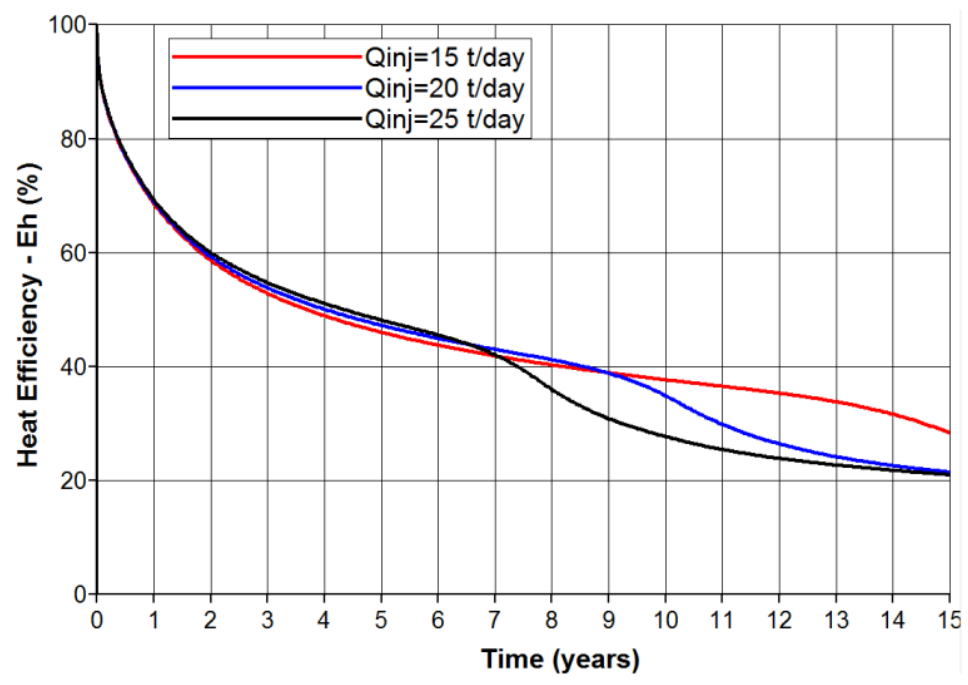

Figure 7. Curves of thermal efficiencies, as a function of injection time, for three different steam injection rates, considering a reservoir thickness of $10 \mathrm{~m}$ (oil net pay). 


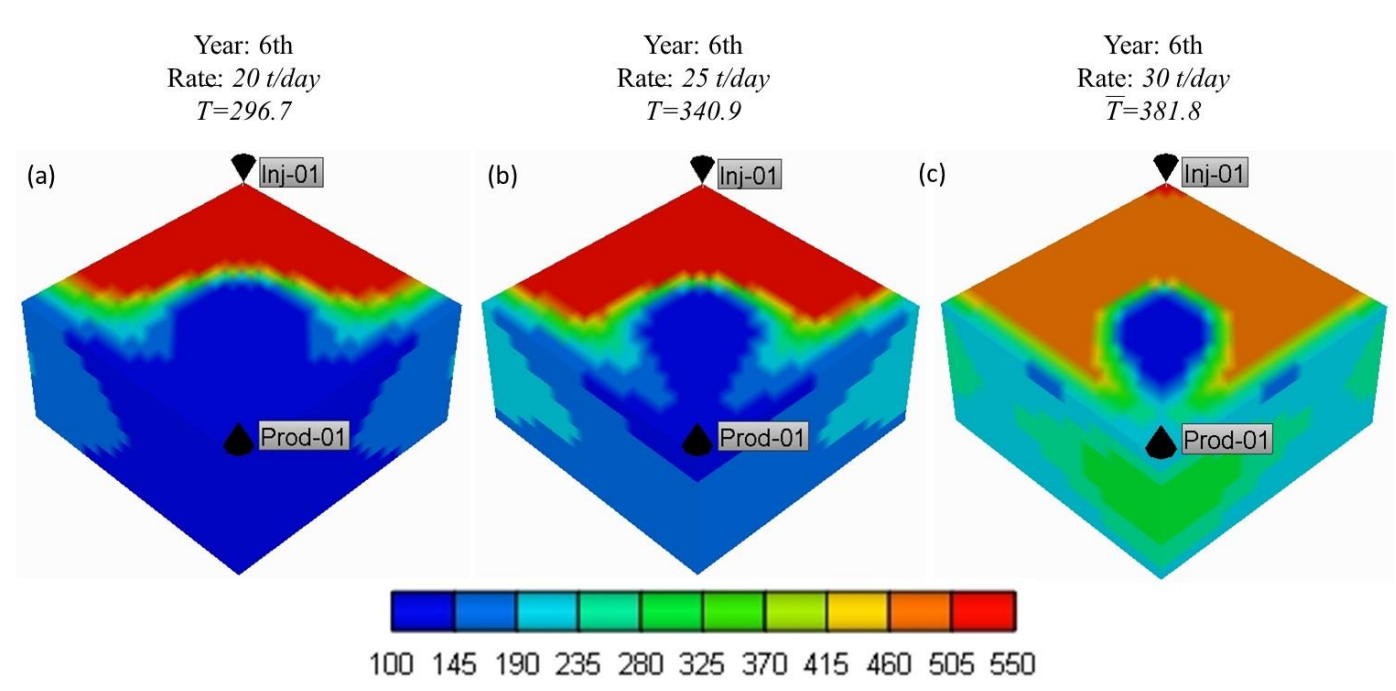

Figure 8. Evaluation of the heat breakthrough for $6^{\text {th }}$ year of project.

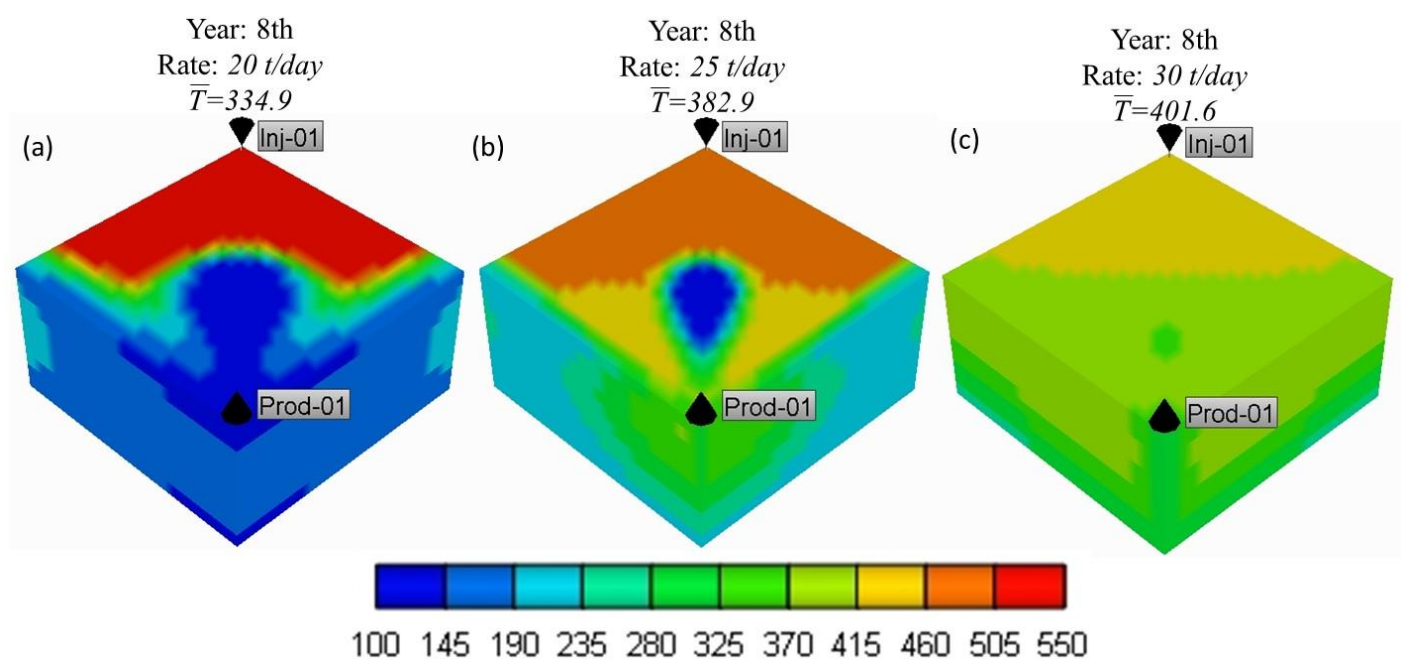

Figure 9. Evaluation of the heat breakthrough for the $8^{\text {th }}$ year of project.

heat breakthrough in the producer well. This happens because there is more remaining heat at higher steam injection rates. However, after the steam breakthrough, there is a sharp drop in thermal efficiency, followed by an inversion in the curves up to the $15^{\text {th }}$ year, where they tend to match again. This phenomenon happens because the energy, in the form of heat within the steam, after the steam breakthrough, keeps being produced, instead of heating the reservoir-rock.

To evaluate the best behavior for the temperature within the reservoir, Figures 8 and 9 present temperature maps for the $6^{\text {th }}$ and $8^{\text {th }}$ years, by keeping the steam injection rate in $20 \mathrm{t} /$ day, 25 $\mathrm{t} /$ day, and $30 \mathrm{t} /$ day. This analysis was performed by considering $c(\%)=100$ and $X(\%)=50$.
From the temperature maps shown in Figure 8, considering three different steam injection rates (20 t/day, $25 \mathrm{t} /$ day, and $30 \mathrm{t} /$ day), one can verify that the steam breakthrough happened at the $6^{\text {th }}$ year of project, but just for $25 \mathrm{t} /$ day and $30 \mathrm{t} /$ day. Figures $8(\mathrm{~b})$ and $8(\mathrm{c})$ show that there is a temperature variation at the region where the producer well is located, indicating that the heat, used to warm up the reservoir, is being produced at the time. The average temperature within the reservoir also is higher when the steam injection rate is $30 \mathrm{t} /$ day, see Figure 8 (c). This temperature variation explains the reason behind the thermal efficiency decrease at the time. In this case, there is an anticipation in the heat production supplied to the reservoir, resulting in a decreased amount of remaining heat within the reservoir rock. At this 


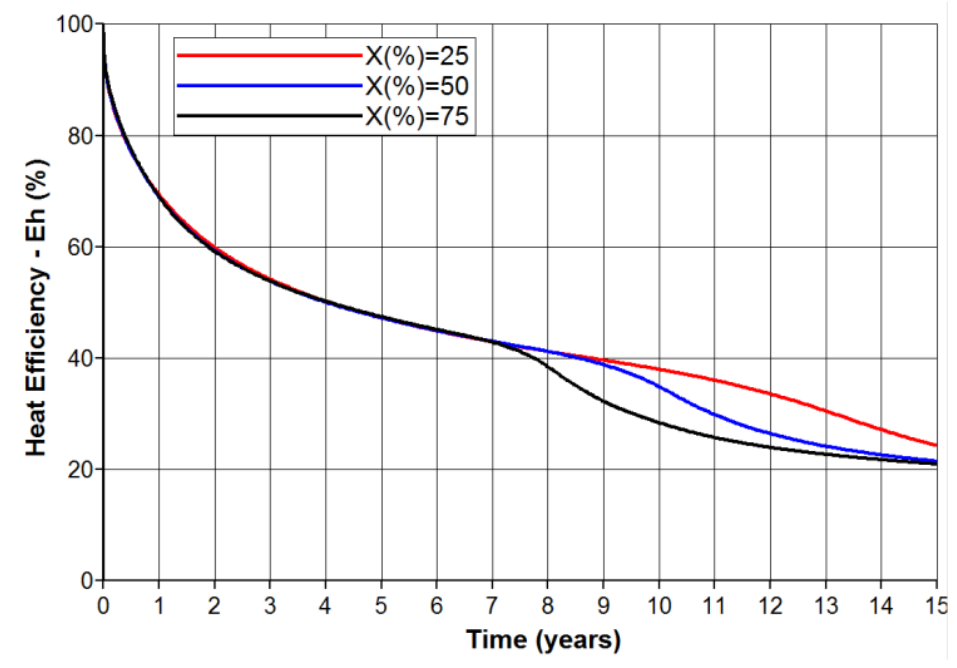

Figure 10. Curves of thermal efficiency as a function of the injection time for three different steam qualities ( $25 \%$, $50 \%$, and $75 \%$ ), considering a reservoir thickness of $10 \mathrm{~m}$ (oil net pay).

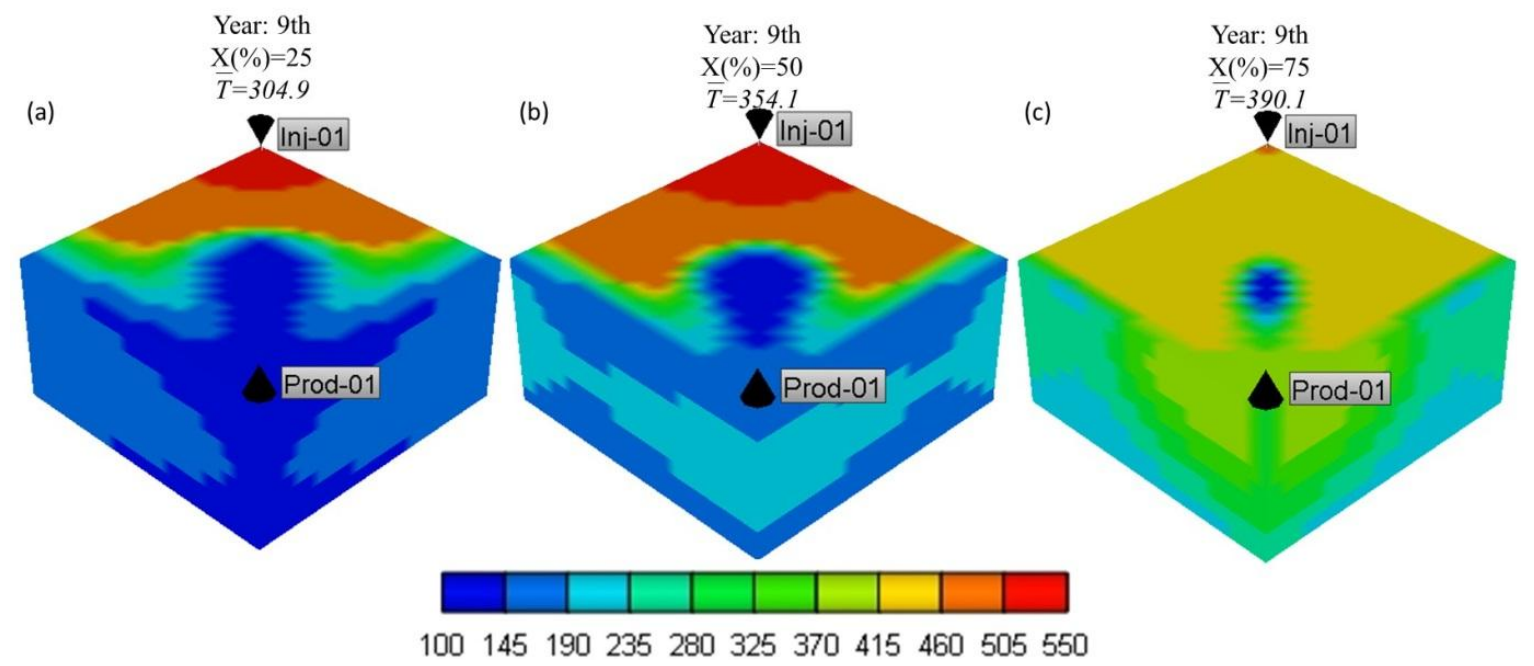

Figure 11. Temperature maps $\left({ }^{\circ} \mathrm{F}\right)$ for the reservoir with steam qualities of $25 \%, 50 \%$, and $75 \%$, considering a reservoir thickness of $10 \mathrm{~m}$ (oil net pay).

same time, for the steam injection of $20 \mathrm{t} /$ day, there was no heat production, hence, the thermal efficiency value was higher for this rate. However, from the $8^{\text {th }}$ year, Figure 9 (a) shows that, for the lower steam rate $(20 \mathrm{t} /$ day), the heat production began through the producer well.

Figures 10 and 11 display the results obtained for the evaluation of steam quality, considering the steam injection rate of $20 \mathrm{t} /$ day, and the well completion for the producer and injector wells along the entire interval $(c(\%)=100)$, with three different steam qualities: $25 \%, 50 \%$, and $75 \%$.
From the results presented in Figure 10, one can verify that, from the beginning up to the $7^{\text {th }}$ year, the thermal efficiencies matched for all steam qualities studied. However, after the steam breakthrough, one can see that, for the highest steam quality $(X(\%)=75 \%)$, there is a sharp drop in the fraction of remaining heat within the reservoir. From Figure 11, one can conclude that the drop happened because the steam bank arrived to the producer well. At that time $\left(9^{\text {th }}\right.$ year), one can observe that the reservoir has a region quite heated, as a consequence of having a high amount of heat in the steam, for the highest steam quality 
$(X(\%)=75)$. From these observations, one can infer that, in that case, much of the heat has already been injected to warm up the reservoir, resulting in a continuous loss of energy in the top and base layers, and also in the producer well.

According to the results obtained, one can conclude that there's a relationship between high steam qualities and steam injection rates and the reduction in the fraction of remaining heat, at the end of the 15 years of project. The high amount of injected heat is lost to adjacent formations and, from the steam breakthrough point on, this amount of heat begins to be produced through the producer well.

\section{CONCLUSIONS}

According to the results obtained from the semisynthetic numerical model, representative of a reservoir from the Potiguar Basin, one can conclude that:

- The highest oil recovery factor was associated to a higher amount of pressure stored within the reservoir, which happened when a steam rate of $20 \mathrm{t} /$ day was injected;

- From the analysis of numerical simulations, one verified that, for the studied reservoir, the highest oil recovery factor was reached at the IPV of 4.2;

- Higher values of steam quality and steam injection rates were associated to the decrease in the fraction of remaining heat. It can be related to the high amount of injected heat that is lost to adjacent formations and, from the point of heat breakthrough on, this amount of heat begins also to be produced;

- According to the results obtained, one can conclude that high steam qualities and steam injection rates are associated to the decrease in the fraction of the remaining heat, at the end of the 15-year project. Higher values of steam injection rates resulted in higher thermal efficiencies, before the steam breakthrough;

- As a result of part of this injected heat being also produced, a sharp decrease in the curves of thermal efficiency occur after the heat breakthrough. In this case, there is an anticipation in the production of the heat supplied to the reservoir, resulting in a decrease in the fraction of remaining heat;

- This study focused on thermal efficiency. Future research will analyze the best results found in this work to complement this research by conducting a study of the economic viability of this process.

\section{ACKNOWLEDGEMENTS}

The authors of this study would like to thank CMG (Computer Modelling Group) for the simulator; LEAP (Laboratório de Estudos Avançados de Petróleo) for the infrastructure used to develop this research; and PPGCEP (Programa de PósGraduação em Ciência e Engenharia de Petróleo) professors for their dedication to this study.

\section{REFERENCES}

Barillas, J. L. M.; Dutra Jr, T. V.; da Mata, W. Improved Oil Recovery Process for Heavy Oil: a Review. Brazilian Journal of Petroleum and Gas, v.2, n.1, p. 45-44, 2008.

Coats, K. H.; George, W. D.; Chu, C.; Marcum, B. E. Three-dimensional simulation of steamflooding. Society of Petroleum Engineers Journal, v.14, n.6, p. 573-592, 1974. http://dx.doi.org/10.2118/4500-PA

Gomaa, E. E. Correlations for predicting oil recovery by steamflood. Journal of Petroleum Technology, v.32, n.2, p. 325-332, 1980. http://dx.doi.org/10.2118/6169-PA

Green, D. W.; Willhite, G. P. Enhanced oil recovery. Richardson: Society of Petroleum Engineers, 1998. 545p.

Mandl, G.; Volek, C.W. Heat and mass transport in steam-drive processes. Society of Petroleum Engineers Journal, v.9, n.1, p. 1-24, 1969. http://dx.doi.org/10.2118/2049-PA

Marx, J. W.; Langenheim, R. H. Reservoir heating by hot fluid injection. Petroleum Transactions, v.216, p. 312-365, 1959. 
Myhill, N. A.; Stegemeier, G. L. Steam-drive correlation and prediction. Journal of Petroleum Technology, v.30, n.2, p. 173-182, 1978. http://dx.doi.org/10.2118/5572-PA

Prats, M. The heat efficiency of thermal recovery processes. Journal of Petroleum Technology, v.21, n.3, p. 323-332, 1969. http://dx.doi.org/10.2118/2211-PA
Satik, C.; Kumar, M.; Defrancisco, S. T.; Hoang, V. T.; Basham, W. H. M. Important modeling parameters for predicting steamflood performance. SPE Reservoir Evaluation \& Engineering, v.10, n.5, p.1-7, 2004. http://dx.doi.org/10.2118/90713-ms 